\title{
LA ETERNIDAD DEL MUNDO ENTRE EDAD MEDIA Y RENACIMIENTO, II
}

\section{ETERNITY OF THE WORLD BETWEEN MIDDLE AGES AND RENAISSANCE, II}

Los artículos que se publican a continuación bajo el título general de «La eternidad del mundo entre Edad Media y Renacimiento» tienen su origen en las ponencias que se leyeron en la Jornada «La eternidad del mundo entre Edad Media y Renacimiento", celebrada en la Universidad de Barcelona el 13 de mayo de 2013. Esta jornada continuaba la anterior, celebrada un año antes también en la Universidad de Barcelona y cuyas ponencias han sido también publicadas en Endoxa, en el volumen 31, pp. 255-371.

Como en el caso anterior, las ponencias presentadas en 2013 aparecen tras haber sido sometidas por sus autores a una profunda revisión. Complementarios de los artículos publicados en 2013, los que se publican ahora cubren un largo espacio de tiempo en el debate sobre la eternidad del mundo: desde las controversias parisinas de finales del siglo XIII (con el articulo de Eudaldo Forment, que examina la intervención de Tomás de Aquino, a medio camino entre las de San Buenaventura y Boecio de Dacia) hasta la segunda mitad del siglo XVII, con dos artículos que nos presentan una posición notoriamente diferente: si por un lado Riccardo Chiaradonna nos sitúa ante la posición antiaristotélica y por ello antieternalista de Campanella, tratando de establecer la concordia entre las tesis platónicas y la ortodoxia cristiana, por su parte el artículo de Marcelino Rodríguez Donís, que examina la exposición y defensa de la tesis eternalista en el manuscrito clandestino Theophrastus redivivus, una verdadera summa de la filosofía radical renacentista, nos expone la articulación del eternalismo con el ateísmo, una conjunción ciertamente nueva y extraña a la gran mayoría de los defensores antiguos, medievales y renacentistas de la eternidad del mundo.

Entre ambos extremos dos artículos examinan las muy interesantes posiciones de dos pensadores singulares, en los que una intención política (más dominante sin duda en el caso del francés Jean Bodin) se conecta con una gran erudición y una rigurosa fundamentación metafísica y teológica, muy diferente ciertamente en un caso y otro. Miguel Á. Granada estudia la defensa de la eternidad del mundo (desde la perspectiva platónica y en polémica tanto con el cristianismo 
como con Aristóteles) por parte de Jorge Gemistos Pletón, mostrando al mismo tiempo que aspectos importantes del posterior pensamiento de Giordano Bruno se encuentran ya claramente delineados en la obra del pensador bizantino. Por su parte Jordi Bayod aborda la polémica antieternalista de Bodin y su conexión con una rigurosa teoría de la absoluta libertad divina, correlativa a una atribución exclusiva de la omnipotencia e infinitud a la divinidad.

El lector reconocerá fácilmente que la metodología y presupuestos de los distintos ponentes es diversa; en unos casos la perspectiva es claramente historiográfica, en otros casos el examen histórico se conecta con una posición favorable a la primacía de la fe. Esta divergencia parece estar conectada y manifestar una diferente posición ante el viejo problema de la relación entre razón y fe, entre religión revelada y filosofía, una cuestión que sin duda alguna subyace a la discusión en torno al problema de la eternidad/novedad del mundo en todos los autores estudiados en las dos jornadas. Ese que hemos denominado «viejo» problema constituye sin duda también un problema central en la modernidad intelectual europea y en su legitimidad, remitiendo cuanto menos a las reflexiones críticas de estudiosos como Leo Strauss, Karl Löwith y Hans Blumenberg, por citar sólo a algunos que han hecho de este problema un momento central de su reflexión.

La jornada que ha dado lugar a estos artículos se celebró en conexión con el proyecto de investigación FFI2012-31573 «Cosmología, teología y antropología en la primera fase de la Revolución Científica (1543-1633)», financiado por el Gobierno Español (Ministerio de Economía y Competitividad).

Miguel Á. Granada 